\title{
Enigma económico de los espíritus dueños del oro: minería de pequeña escala de oro en Sudamérica
}

\section{Víctor Hugo Pachas}

Universidad Nacional Federico Villarreal

doi: $10.46476 /$ ra.v2i1.43

\section{Resumen}

En esta tesis ${ }^{1}$ se discuten tres preguntas de orden cualitativo: ¿Cómo experimentan la secularización los espacios de actividades de minería de pequeña escala en los países andinos (Bolivia, Colombia, Ecuador y Perú)? ¿Qué sustento cultural tienen los mineros de pequeña escala para poner en práctica su convivencia con la naturaleza y su vida diaria? ¿Cómo se asemeja y se diferencia la minería de pequeña escala respecto de la sociedad hegemónica? Metodológicamente, el investigador realizó 14 etnografías durante 4 años (2012-2016) en los países indicados, donde se recolectó información a partir de entrevistas semiestructuradas (160), grupos focales (20), árboles genealógicos (4) y observación participante. Los mineros experimentan su diversidad religiosa sobre la base del animismo andino que se readapta de espacios agrícolas a mineros, expresado en un ritual de pago, el cual da a conocer que pese a ser una actividad tradicionalmente masculina, ritualiza a la mujer y promueve acuerdos verbales para evitar conflictos. Así, concluimos la minería de pequeña escala permanece en la periferia de la sociedad hegemónica.

1. Tesis de la UNMSM para obtener el grado de Doctor en Ciencias Sociales en la especialidad de Antropología 


\section{Problema de investigación}

Esta investigación reflexiona sobre la dinámica entre el hombre y la naturaleza, a partir de una investigación etnográfica basada en el análisis simbólico de la trama cultural que se teje en el marco de la economía de la minería de pequeña escala de oro, que tiene correlatos de similitudes y diferencias empíricas en los países del área andina (Bolivia, Colombia, Ecuador y Perú). Su consideramos que la cultura andina está impregnada de religiosidad, mis planteamientos discuten tres preguntas en orden cualitativo:

- ¿Cómo se experimenta la secularidad en los países andinos de Sudamérica que tienen presencia de actividades de minería de pequeña escala?

- ¿Qué sustento cultural tienen los mineros de pequeña escala para poner en práctica su convivencia con la naturaleza y su vida diaria?

- ¿Cómo se asemeja y se diferencia la minería de pequeña escala respecto de la sociedad hegemónica?

Se postula una hipótesis general, la cual indica que «en la actualidad, en los países de Bolivia, Colombia, Ecuador y Perú, la gran parte de la población rural que se involucra en la minería de pequeña escala de oro, tiene un pensamiento basado en el establecimiento de acuerdos verbales, principio que es producto de sus creencias en los espíritus que habitan las minas» (Pachas 2019). Asimismo, las hipótesis específicas son:

- Los mineros transitan por diferentes códigos religiosos como el católico, evangélico y andino, lo que diversifica su universo religioso.

- La minería de pequeña escala tiene como sustento cultural ritualizar a la mujer; el estatus social que adquiere el minero para establecer acuerdos verbales y evitar conflictos como parte de una cultura basada en la incertidumbre.

- La minería de pequeña escala es aislada por la sociedad hegemónica y tiene una fuerte tendencia a desaparecer; sin embargo, ha generado una cultura basada en la incertidumbre. 


\section{Metodología y conceptos básicos}

La posición del observador, como participante por 15 años en los procesos descritos, es el principal aporte cualitativo a la base de información empírica que sirve de sustento a esta investigación. Para esta tesis doctoral se realizó una investigación etnográfica en Bolivia, Colombia, Ecuador y Perú, donde se recolectó información mediante entrevistas semiestructuradas (160), grupos focales (20), árboles genealógicos (4) y observación participante (2012- 2016). Asimismo, se realizó 14 etnografías y se utilizó los siguientes criterios para seleccionar los casos: i) la unidad de análisis etnográfico es un derecho minero, sea concesión, denuncio o petitorio formal e informal; ii) nivel de productividad de los yacimientos de oro; iii) tradicionalidad de la minería de pequeña escala en el área de investigación; iv) zonas fronterizas de países andinos de Sudamérica; v) convivencia de minería de pequeña escala con violencia de grupos armados; vi) presencia de población quechua y aymara en el área de investigación.

Las 14 etnografías fueron específicas para cada actor de la cadena de producción de oro; estos últimos son: los recolectores que seleccionan oro de los desperdicios de la mina; los mineros empleados que solo trabajan para un minero titular o invitado; los mineros invitados que explotan oro mediante acuerdos con los titulares de algún derecho minero; y los titulares de algún derecho, quien tienen alguna figura legal aprobada por los países mencionados.

Se realizó cuatro etnografías sobre recolectores: la Asociación de Palliris Rayito de Sol de Huanuni (Oruro, Bolivia); los barequeros de la vereda de Caño Negro (Caqueta, Colombia); los Jancheros Ecológicos y Protectores del Medio Ambiente (Azuay, Ecuador) y la Asociación de Mineros Artesanales Chichiqueros (Madre de Dios, Perú).

Tres etnografías sobre mineros empelados: el grupo de trabajo Juventud Unida de la cooperativa Bella Rica (Azuay, Ecuador); los Halcones Rojos de Mollehuaca que trabajan informalmente en la concesión de la Empresa Minera Rumbo (Arequipa, Perú) y el grupo de trabajo Mineros Amigos del Bosque de la Empresa Minera Milagritos Inés, (Madre de Dios, Perú).

Cuatro etnografías sobre mineros invitados: la Cooperativa China Ltda y la Cooperativa Molle Ltda, (Tipuani, Bolivia); los mineros de la draga Felipe V (Caquetá, Colombia); el grupo de trabajo Los Picapiedra de la Asociación Fronteras Vivas (Zamora Chinchipe, Ecuador) y la Asociación de Productores Mineros Artesanales de Otoca en la Minera Elefante Dorado (Lucanas, Perú).

Tres etnografías sobre el titular de algún derecho minero: la cooperativa Minera Huayna Potosi II (Oruro, Bolivia); la Cooperativa Minera Aurífera de Balseros 
Bolivianos (Beni, Bolivia) y la Sociedad de Trabajadores Mineros SA (Lucanas, Ayacucho).

En esta investigación no se utiliza el concepto de secularización por carecer de contenido respecto a la situación que implica para los países andinos. Siguiendo a Bastian (1997), América Latina nunca tuvo una modernidad, al mejor estilo europeo, por lo que no se podría utilizar el concepto de secularización. Para describir el proceso que se observa en los países andinos de diversificación de diferentes grupos religiosos se utilizará el concepto de diferenciación funcional de Luhmann (2007), para comprender una sociedad altamente diferenciada con medios de comunicación simbólicamente generalizados. Caracterizar el medio de comunicación, simbólicamente generalizado de la religión, implica mirar la diversidad de opciones simbólicas o códigos que se estructuran dentro de ella.

Los códigos están formados por procesos comunicativos complejos y con niveles diversos de relación entre religión y moral. En circunstancias más locales/ familiares y propias, la moral se interioriza en la religión, lo que asume un rol protagónico y determinante del mundo comunicacional. En otras circunstancias de mayor interacción pública-global y de redes sociales, la religión se moraliza y pierde su función de restringir las comunicaciones. Para el análisis del código base se considera un análisis descriptivo del símbolo ritual, que tiene sus correlatos en mantener la cohesión social. En el enfoque de la sociedad hegemónica y su correlato con la minería de pequeña escala, se observó dosaspectos. La teoría de Luhmann propone que, si las comunicaciones no son fluidas entre los sistemas, el sistema tiende a agotarse y fusionarse con otro sistema. Sin embargo, la data empírica que se observónos conduce aotro criterio, mucho más complejo, el sistema de la minería de pequeña escala ha acentuado tanto su sistema social que ahoraha aprendidoa convivir con comunicaciones itinerantes. Esta convivencia de comunicaciones itinerantes con la sociedad hegemónica ha formado una cultura sobre la base decomunicaciones simbólicas.

\section{Principales hallazgos}

La religión, como medio de comunicación simbólica, permite observar dinámicas complejas en los países andinos de Sudamérica, tratados en esta investigación etnográfica, ya que combina matices de cosmovisiones tradicionales y otras más institucionalizadas. En el área andina, se ha definido hasta tres códigos comunicativos que se relacionan constantemente: código animista andino, código de la trinidad católica y santos conectores, y código de la biblia como moralidad. Sin excepción, en los casos evaluados en esta investigación etnográfica, la comunicación simbólica de la religión se ha consolidado de forma flexible y abierta para facilitar la comunicación entre los códigos, la yuxtaposición de convivencia entre el animismo andino, la trinidad y santos católicos, y la biblia como moral, demuestra 
la capacidad de readaptación constante, a comunicaciones que aparentemente serían mutuamente excluidas. De tal forma, la religión andina tiene como código base al animismo andino, que utiliza diversas formas de comunicación y que es posible aún identificar en el siglo XXI; no se sostiene que este código sea la lógica religiosa andina por excelencia sino más bien se postula a su vigencia como parte de la cultura andina.

El caso de los espíritus dueños del oro, que se presenta en esta investigación, tienen la particularidad de manifestarse a los mineros mediante sueños, con la dueña del oro, o físicamente en el aspecto del Muki o Chinchillico, quienes reciben dádivas que contienen el secreto de la ubicación de vetas ricas en oro; a cambio el minero celebra rituales de "pagos», que sintetizan la idea de acuerdos verbales que guían todo su sistema social. El código animista andino contempla estas particularidades, pero también sus relaciones con los otros códigos. Esto trae como consecuencia que el usuario utilice códigos en diferentes circunstancias: cuando está en sus lugares de origen utiliza códigos como el de la trinidad católica y los santos conectores o si es evangélico el código de la biblia como moralidad, sin mayores problemas; además, cuando está en la mina respeta la diversidad religiosa y se adapta. Estas particularidades definen la alta diferenciación funcional que sucede en el área andina.

La justificación cultural que tienen para la puesta en práctica de la minería de pequeña escala y su convivencia con la naturaleza, se sintetiza en los rituales de «pago» que realiza a la veta de oro. La dueña del oro, principalmente, es entendida como el espíritu mujer que tiene el control de la naturaleza y que autoriza el uso de los recursos naturales. Los «pagos» están representando la celebración del acuerdo verbal que tiene el minero con los espíritus de las minas para la convivencia con la naturaleza. La mujer es el símbolo dominante en la ritualidad a la dueña del oro. Pese a considerar a la minería como una actividad estrictamente masculina, los mineros simbolizan a la mujer porque necesitan de su ayuda mientras ellos están en la mina, la mujer puede quedarse con la familia y obtener recursos económicos inmediatos para el sostenimiento de todos realizando trabajos eventuales. Por otro lado, la mujer participa en actividades mineras como: gestión de operaciones mineras, abastecimiento de insumos, trabajos en desmontes y en el procesamiento de oro. Este símbolo dominante sintetiza las principales situaciones de incertidumbre en las que se involucra el minero, como los acuerdos verbales con sus coetáneos. El rito a la dueña del oro significa para el minero un rito de pasaje hacia un estatus con mayor poder y legitimidad para establecer acuerdos verbales con sus coetáneos. Desde el sueño con la dueña del oro, hasta concluir con el pagacho a la veta, el minero atraviesa por un cambio en su estatus, ahora puede establecer acuerdos verbales con la confianza que estos pueden ser duraderos. 
Este acuerdo verbal o autopoiesis desencadena múltiples comunicaciones autopoiéticas con todo el sistema social, haciendo flexible la interacción entre los sistemas religiosos, económicos y otros. De forma que este principio pasa de un plano religioso a un plano moral de los usuarios del sistema social; los acuerdos verbales entre mineros funcionan para poner en marcha el sistema social, haciendo múltiples operaciones de autopoiesis para la existencia de operaciones mineras. El principio de la autopoiesis trae consigo la masificación de comunicaciones en el sistema a partir de acuerdos verbales expresados principalmenteen la flexibilidad de estrategias de parentesco para formar asentamientos mineros, consolidar pueblos mineros y extender este tipo de minería por nuevas regiones en busca de yacimientos más productivos. Los mineros necesitan asociarse con otros actores sociales en el campo para establecer operaciones mineras; es así que esta necesidad está relatada en los acuerdos verbales. Sin embargo, también el sistema social observa casos de incumplimiento de acuerdos verbales, los que invitan nuevamente a la praxis autopoiética del sistema, haciendo un proceso sumamente diferenciado y complejo.

Un aspecto que es importante subrayar, es que los «pagos», como justificaciones culturales, envuelven a los mineros en mitologías respecto a la procedencia del oro y el rol que tiene el minero, incluyendo algunos relatos del mismo tiempo del imperio de los incas: los mineros son seres que tienen la tarea mítica de recoger las «lágrimas del sol», dios protector del hombre andino.

El sistema de la minería de pequeña escala es caracterizado por otros sistemas como un conjunto de «hordas salvajes» y "primitivos» por el carácter informal e ilegal de sus operaciones mineras para los estados en Sudamérica, además del terrible impacto ambiental que ocasiona y la vulnerabilidad de derechos de la mujer. El sistema de minería de pequeña escala no tiene las particularidades de dar solución a estos problemas, ya que no encuentra canales de comunicación fluidos con otros sistemas hegemónicos, los cualessolo han moralizado peyorativamente al sistema de la minería de pequeña escala.

Esta investigación etnográfica ha venido sosteniendo que la moralización se expresa públicamente llevando al extremo las limitaciones del sistema de la minería de pequeña escala, aislándolo y dejándolo sin comunicación dentro del sistema hegemónico. Esto ocasiona la frustración de los procesos de formalización minera, la paradoja del uso de mercurio y desestructuración del mismo sistema. La continuidad de la reproducción de incomunicaciones del sistema de la minería de pequeña escala con la sociedad hegemónica es la historia de una incertidumbre, que en el último siglo ha caracterizado a los mineros de oro.

Por las mismas razones de caracterizar la incertidumbre del sistema, producto de la moralización de la sociedad hegemónica, es que esta investigación ha explicado 
que, de acuerdo con el análisis sistémico, por la falta de comunicaciones con la sociedad hegemónica existe una fuerte tendencia a la desestructuración del sistema de la minería de pequeña escala. Claramente es una opción, ya que los mineros, que provienen de la agricultura, podrían migrar a otra economía más rentable. Sin embargo, también el análisis sistémico me indica que la institucionalidad de la sociedad es muy frágil en los países andinos y ello contribuye a que el sistema de la minería de pequeña escala, con los años, ha consolidado una autopoiesis que le permite convivir con su propia incertidumbre, causada por la escasa comunicación con la sociedad hegemónica

\section{Referencias bibliográficas}

Pachas, V. (2019). Enigma económico de los espíritus dueños del oro: minería en pequeña escala de oro en Sudamérica. Tesis Doctoral en Ciencias Sociales en la especialidad de Antropología. UNMSM, Lima. http://cybertesis.unmsm.edu.pe/handle/cybertesis/11148

Luhmann, N. (2007). La sociedad de la sociedad. México D. F. Editorial herder.

Bastian, J. (1997). La mutación religiosa en América Latina. México D.F. Fondo de Cultura Económica. 
